\title{
Protocol: Personality assessment as a support for referral and case-work in treatment for substance use disorders (PASRC-study) Morten Hesse* and Mads K Pedersen
}

\author{
Address: University of Aarhus, Centre for Alcohol and Drug Research, Købmagergade 26E, 1150 Copenhagen C, Denmark \\ Email: Morten Hesse* - mh@crf.au.dk; Mads K Pedersen - mkp@crf.au.dk \\ * Corresponding author
}

Published: 25 April 2008

BMC Psychiatry 2008, 8:30 doi:10.1/86/147|-244X-8-30

This article is available from: http://www.biomedcentral.com/147I-244X/8/30

(C) 2008 Hesse and Pedersen; licensee BioMed Central Ltd.

This is an Open Access article distributed under the terms of the Creative Commons Attribution License (http://creativecommons.org/licenses/by/2.0), which permits unrestricted use, distribution, and reproduction in any medium, provided the original work is properly cited.
Received: 31 January 2008

Accepted: 25 April 2008

\begin{abstract}
Background: Assessment of co-morbid personality disorders in substance use disorders may lead to important insights concerning individual patients. However, little is known about the potential value of routine personality disorder assessment in a clinical context.

Methods: Patients are adults with past-year substance dependence seeking treatment at a centralized intake unit for substance abusers in the City of Copenhagen. A randomized controlled trial of assessment of personality disorders and individual feedback vs. a general life situation interview. Patients are followed at 3 and 6 months post-treatment

Discussion: If routine personality assessment improves outcomes of substance abuse treatment, the clinical implication is to increase the use of personality disorder assessment in substance abuse treatment settings.
\end{abstract}

Trial registration: Current controlled trials ISRCTN3985I 689

\section{Background}

Substance use disorders and personality disorders often co-occur $[1,2]$. Patients with personality disorders are commonly seen in treatment programs for substance abuse, consume a disproportionate amount of staff time, and are more likely to drop out from substance abuse treatment interventions [3,4].

At the same time, therapists and other professionals tend to react negatively to patients with personality disorders at an emotional level [5], this is especially the case with cluster B (dramatic/erratic) personality disorders [6].

Even if patients with personality disorders benefit from treatment, they often remain more symptomatic than patients without personality disorders, and remain at a lower level of functioning $[7,8]$.

Therefore, treatment that meets the needs of patients with substance abuse and personality disorders is needed. Recently, some studies have shown that integrated treatment for personality disorders and substance abuse may be superior to treatment that focuses solely on substance abuse treatment [9-11].

This randomized experimental study is designed to assess whether systematic assessment of personality disorders improves outcomes, vs. assessment of Axis I disorders alone. 
The objective of this study is to estimate the effect of routine assessment of co-morbid axis II disorders in a centralized intake unit for substance use disorders.

\section{Method \\ Design}

The study is a randomized experimental trial comparing assessment of Axis I disorders alone with assessment of both Axis I disorders and Axis II disorders. For both treatment conditions, patients are given feedback about the results of assessment and offered the opportunity to have their key-worker receive the same feedback.

\section{Participants/setting}

Participants are adults seeking treatment for a substance use related disorder at the Central Intake Unit (CIU) in Copenhagen, Denmark (Købmagergade 26E, St., 1150 Copenhagen C).

\section{Referral and recruitment}

Patients are recruited by caseworkers. The management of the intake unit and the management of the centre have instructed all caseworkers to ask all new referrals or those referred for a change in treatment to participate in the study.

Caseworkers inform patients that the study concerns assessment of psychological problems, behaviour and other disorders, and that patients will be randomly assigned to one of two types of interviews. The primary interviewer later gives detailed information about the study procedure.

\section{Inclusion criteria}

To be eligible for the study, patients must satisfy the following criteria:

- Be at least 18 years of age.

- Not currently be psychotic or have a known diagnosis of schizophrenia excluding patients from treatment at the intake unit.

- Not currently be involved in an ongoing treatment for a drug or alcohol problem. Patients who are currently involved in treatment for alcohol or drug abuse will, however, not be referred to the CIU.

- Have past-year substance dependence, as indicated by a score on the SDS of 3 or more for either alcohol or drugs.

- Speak Danish or English fluently.

- Give informed consent.
The assessment and feedback takes place in the first three weeks of treatment.

Table 1 gives an overview of the interviews and questionnaires conducted at the different assessment times. Figure 1 represents the research procedure schematically. Figure 2 contains the expected participant flow.

\section{Outcome criteria}

The main outcome criterion will be the following: Improvement in at least one of the following areas, described as a $30 \%$ decline in score, with no concurrent deterioration in any area: global functioning, as measured by the Work and Social Adjustment Scale [12]; psychiatric symptoms, as measured by the Kessler $6+[13,14]$; substance use, as measured by the Opiate Treatment Index drug use indicator [15]; treatment engagement, as measured by treatment staff, using the treatment engagement scale from DATOS [16].

Secondary outcome criteria will be

- Retention in treatment, defined as being retained in the same treatment that patients were first referred to after their contact with the intake unit at 3 and 6 months follow-up, or having completed that treatment as planned.

- Understanding of one's own personality and the impact that personality has on others, as rated by an independent interviewer [17].

- Readiness to change dysfunctional behaviour, work with emotional problems, change illicit drug use, and change alcohol use, as measured by brief 4 -item questions, adapted from the smoking cessation literature [18].

Outcome criteria will be assessed at 3 and 6 months follow-up.

\section{Intake procedure}

At intake to the CIU, patients undergo a routine intake interview with a key-worker that includes the Addiction Severity Index [19]. After the completion of the intake interview, patients are informed by the caseworker of the fact that a study of psychopathology is ongoing at the unit. If the patient agrees to receive further information, a researcher is contacted, which immediately comes to the office of the key-worker to meet the patient and schedules an intake interview.

\section{Baseline interview}

At the baseline interview, the interviewer informs the patient of the study, and explains that the study focuses of psychological and behavioural problems that people with substance abuse regularly encounter. He then explains 


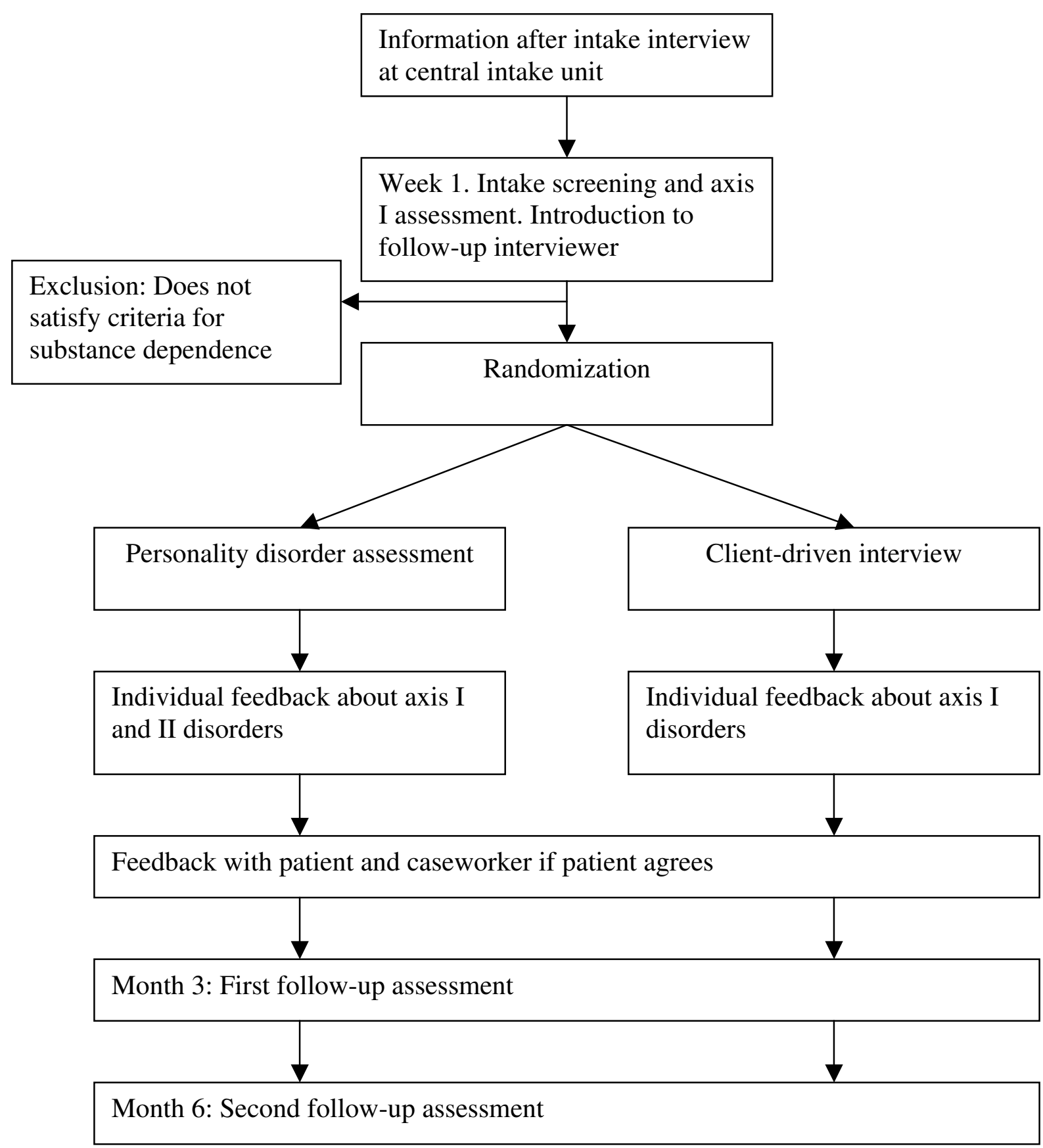

Figure I

Flowchart of the process from information to follow-up.

that there are two different interviews, and that patients will be randomly assigned to one of two types. If asked, he will explain that he does not yet know what kind of interview he will conduct the second time they meet, but he will give a further explanation at their second appointment. If the patient gives consent to participate in the study, a brief structured assessment of axis I disorders is conducted. The assessment is kept brief, in order to reduce assessment reactivity, i.e., the effects that assessment can have on treatment outcomes [20].

The instruments used are therefore chosen to be brief, but have strong indications of validity: 


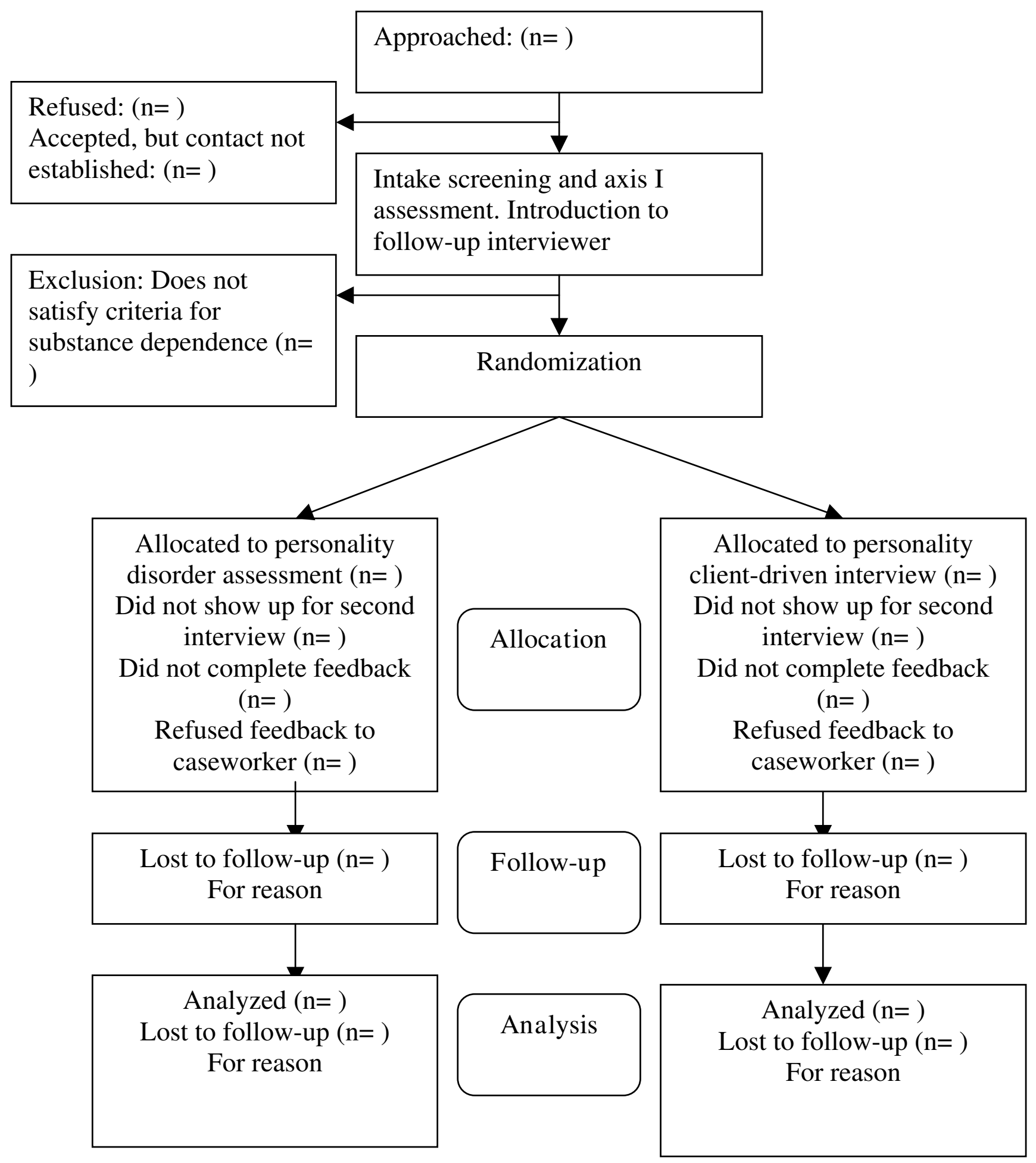

Figure 2

Flowchart of participants. 
Table I: Instruments at different assessment moments

\begin{tabular}{lccc}
\hline & Baseline & Follow-up & Follow-up \\
\hline Interview: & & & \\
SAPAS [22, 23] & $*$ & $*$ & $*$ \\
ASRS [14] & $*$ & $*$ & $*$ \\
K6 [32] & $*$ & $*$ & $*$ \\
OTI [15] & $*$ & $*$ & $*$ \\
SDS - alcohol [2I] & $*$ & $*$ & $*$ \\
SDS - drugs [2I] & $*$ & $*$ & $*$ \\
WAI [29] & & $*$ & \\
Ratings of the feedback & & $*$ & \\
procedure - VAS & & & \\
Clinician rated: & & $*$ & $*$ \\
CGI-externalizing [23] & & $*$ & $*$ \\
CGI-substance use [23] & & $*$ & $*$ \\
GAF [23] & & $*$ & \\
WAI [29] & & & \\
\hline
\end{tabular}

Notes: SAPAS: Standardised Assessment of Personality - Abbreviated Scale. ASRS: Adult ADHD Self-Report Scale. K6: Kessler 6. OTI: Opiate Treatment Index. SDS: Severity of Dependence Scale. WAI: Working Alliance Inventory. VAS: Visual analogue scales. CGI: Clinical Global Impression. GAF: Global Assessment of Functioning.

- Anxiety/depression is assessed with The Kessler 6 interview [14].

- Attention Deficit/Hyperactivity Disorder is assessed with the Adult ADHD Self-Report Scale [14].

- Illicit substance dependence and alcohol dependence are both assessed by means of the Opiate Treatment Index substance use items [15].

- Severity of alcohol and illicit drug dependence will be assessed by the Severity of Dependence Scale [SDS] [21].

- Personality disorder severity is assessed with the Structured Assessment of Personality - Abbreviated Scale [SAPAS] [22,23].

If the patient does not speak Danish or English well, does not screen positive for substance dependence as indicated by an SDS score of 3 or more for either alcohol or drugs, a feedback session is scheduled, and the patient is informed that based on his data, we wish to give him individual feedback on the next session.

If the patient satisfies inclusion criteria (speaks Danish or English; SDS > 3; gives informed consent), a second interview is scheduled. The interviewer will also schedule a meeting with the researcher conducting follow-up interviews.

The patient is then randomized to either experimental or control conditions.

\section{Second interview - experimental condition}

If the patient is randomized to the experimental condition, the second interview will be an assessment of axis II disorders. The patient will first receive a brief description of what personality disorders is, and be given a brief description of personality disorders as inflexible, maladaptive patterns of behaviour that cause significant problems or distress for themselves or others.

The interview will consist of the following elements:

- The Alcohol Use Disorder and Associated Disorders Interview Schedule (AUDADIS) section for avoidant, dependent, obsessive-compulsive, paranoid, schizoid and histrionic personality disorder [24]. Added items taken from the Parker Personality inventory will be taken in to reflect schizotypal personality disorder and narcissistic personality disorder [25].

- The NPI-16 will be added as a measure of narcissism [26].

- The Psychiatric Research Interview for Substance and Mental Disorders (PRISM) [27,28] will be used to assess borderline and antisocial personality disorder.

Following this, patients will be asked if they have any questions, and thereafter the interviewer will proceed with the interview. The interview will contain the following elements.

The interviewer will be trained through role-plays in administering the interview package. For the PRISM, taped interviews will be co-rated to assess the inter-rater reliability of coding.

\section{Second interview: control condition}

The control condition will contain an interview of up to one hour, where the patient chooses focus based on a list of items (substance use problems; family; friends; work/ education; etc). The interview is client-driven and follows an ethnographic approach.

These interviews are taped and used as the basis for a condensed summary in the feedback

\section{Randomization and blinding}

Randomization will be conducted by means of a predefined list of random numbers, stratified by predefined characteristics, which will not be disclosed at this point to reduce risk of breaking of blind. Randomization is executed according to a list, the allocation sequence of which was computer-generated by one of the researchers $(\mathrm{MH})$. The interviewer will be blinded to randomization at the baseline interview. 
The follow-up interviewers will be introduced to the patients at the baseline interview, to assure blinded follow-up assessments.

\section{Withdrawal}

A participant can withdraw from the trial at any point, although information already given to caseworkers cannot be withdrawn. Participants who withdraw from the trial treatment will not be asked to attend the follow-up appointments, and will be deleted from all files.

\section{Feedback and psychoeducation procedure}

Patients will receive individual feedback first. The feedback is inspired by psychoeducation procedures [17]. For each diagnosis for which a positive result is found, patients are first prompted about their knowledge of the disorder, and then given their test results. Test results will involve diagnoses and possible treatment options and implications (e.g., psychotherapy and/or medication for anxiety/depression; skills training and/or medication for attention deficit/hyperactivity disorder). For personality disorders, treatment implications, resources and relevant treatment options are summarized in Table 2.

\section{Follow-up procedure}

Trained interviewers will make contact with study participants before randomization, but after intake interview. Interviewers will be blinded to randomization status. The follow-up interview will contain the same elements as the baseline interview (i.e., the $\mathrm{K} 6$, the ASRS, the WSAS, the OTI, and the SDS). Also, patients will be asked to rate the value of the feedback procedure on visual analogue scales representing the skills of the interviewer (on a line ranging from "extremely unskilled" to "extremely skilled"), his knowledge (from very little knowledge, to highly knowledgeable), his degree of interest in the patient, his understanding of the patient, the value of the feedback for the treatment, the value of the treatment for the patient, how much thought the patient has given the feedback, and how much work he has done in regard to the issues discussed in the feedback.

Finally, the patient is asked to rate his alliance with the caseworker using the Working alliance inventory, patient version [29].

Table 2: Treatment implications, personal resources, and relevant treatment options for each of the ten personality disorders

\begin{tabular}{|c|c|c|c|}
\hline $\begin{array}{l}\text { Personality } \\
\text { disorder }\end{array}$ & Implications & Resources & Treatment options \\
\hline Paranoid & $\begin{array}{l}\text { Problems dealing with high expressed emotion; needs } \\
\text { time to build trust; needs great patience; problems } \\
\text { with groups, especially confrontative groups. }\end{array}$ & $\begin{array}{l}\text { Careful, able to cope in } \\
\text { realistic danger; protects } \\
\text { own privacy }\end{array}$ & $\begin{array}{l}\text { Counselling; inpatient treatment in small } \\
\text { wards with great flexibility; not } \\
\text { exploratory psychotherapy [10] }\end{array}$ \\
\hline Schizoid & $\begin{array}{l}\text { Problems dealing with high expressed emotion; needs } \\
\text { great patience; does not benefit from requests for } \\
\text { participation in social activities. }\end{array}$ & $\begin{array}{l}\text { Able to deal with being } \\
\text { alone; }\end{array}$ & $\begin{array}{l}\text { Counselling; possibly inpatient treatment } \\
\text { in small wards with great flexibility [10] }\end{array}$ \\
\hline Schizotypal & $\begin{array}{l}\text { Problems dealing with high expressed emotion; needs } \\
\text { great patience; problems with groups; needs time to } \\
\text { build trust. }\end{array}$ & $\begin{array}{l}\text { Creative, independent } \\
\text { thinking }\end{array}$ & $\begin{array}{l}\text { Counselling; possibly inpatient treatment } \\
\text { in small wards with great flexibility [10]; } \\
\text { antipsychotic medication }\end{array}$ \\
\hline Antisocial & $\begin{array}{l}\text { Impulse actions; "plays the game"; needs straight talk } \\
\text { from counsellor or case worker; transgresses } \\
\text { boundaries in treatment; }\end{array}$ & $\begin{array}{l}\text { Great potential for action } \\
\text { under many circumstances }\end{array}$ & $\begin{array}{l}\text { Therapeutic community or similar } \\
\text { treatment [33]; regular addictions } \\
\text { treatment; cognitive-behavioural } \\
\text { interventions, or similar }\end{array}$ \\
\hline Borderline & $\begin{array}{l}\text { Impulse actions; transgresses boundaries in treatment; } \\
\text { needs to learn to cope with emotion; chaotic } \\
\text { relationships to therapists }\end{array}$ & $\begin{array}{l}\text { Sensitive and able to } \\
\text { experience emotions }\end{array}$ & $\begin{array}{l}\text { Psychotherapeutic treatment; } \\
\text { antidepressants; antipsychotics; inpatient } \\
\text { treatment; long-term involvement }\end{array}$ \\
\hline Histrionic & $\begin{array}{l}\text { Flirts and appears shallow and superficial to others; } \\
\text { has difficulties focusing on own situation and issues }\end{array}$ & Charming and outgoing & $\begin{array}{l}\text { Psychotherapeutic treatment; counselling; } \\
\text { inpatient treatment; cognitive-behavioural } \\
\text { interventions }\end{array}$ \\
\hline Narcissistic & $\begin{array}{l}\text { Appears grandiose and arrogant; makes it difficult for } \\
\text { staff members to intervene ("scares" away all criticism) }\end{array}$ & Has ability to feel pride & $\begin{array}{l}\text { Inpatient treatment for drug misuse; self- } \\
\text { change program, cognitive-behavioural } \\
\text { interventions }\end{array}$ \\
\hline Avoidant & $\begin{array}{l}\text { Difficulty getting out with new people; stays in "safe } \\
\text { zones", and has difficulty trying out new treatment } \\
\text { options or seeking social support or employment }\end{array}$ & $\begin{array}{l}\text { Self-protective; sometimes } \\
\text { able to stay out of trouble by } \\
\text { keeping away }\end{array}$ & $\begin{array}{l}\text { Psychotherapeutic treatment; } \\
\text { antidepressants; inpatient or outpatient } \\
\text { treatment; individual counselling and case } \\
\text { management }\end{array}$ \\
\hline Dependent & At high risk of abusive relationships & $\begin{array}{l}\text { Good ability to form working } \\
\text { relationships; good } \\
\text { compliance }\end{array}$ & $\begin{array}{l}\text { Psychotherapeutic treatment; } \\
\text { antidepressants; inpatient or outpatient } \\
\text { treatment; individual counselling }\end{array}$ \\
\hline $\begin{array}{l}\text { Obsessive- } \\
\text { compulsive }\end{array}$ & $\begin{array}{l}\text { Difficulties concluding in counselling or therapy } \\
\text { settings; attempts to control counsellor, and other } \\
\text { professionals }\end{array}$ & Sticks to goals & Psychoeducation; \\
\hline
\end{tabular}


At each interview point, the caseworker is asked to rate the patient using the clinical global impression scale with anchor points for alcohol and drug abuse [23], externalizing behaviour [23], and GAF [23], and to complete the Working Alliance Inventory, clinician version [29].

\section{Data handling and record keeping}

Patient information will only be accessible to the research team. All data will be link-anonymised so that no patient identifying information will be kept with raw data. All files will be kept with the local research teams in a locked and secure cabinet. Electronic data will be stored on a central computer at the research centre.

A personal feedback letter will be given to the patient, in which the patient appears only with his or her first letter. If the patient agrees that the information in the personal feedback should be shared with the caseworker, then the same letter will be given to the caseworker. Raw data will, however, only be kept and stored by the Centre for Alcohol and Drug Research.

\section{Outcome evaluation}

A single measure of outcome will be used as the primary outcome measure: The proportion of areas in which a $30 \%$ reduction occurred at each follow-up wave (K6, WSAS, and OTI substance use). This measure can theoretically range from -3 (deterioration in all areas) to +3 (improvement in all areas.

The data will be analyzed with mixed effects ordinal regression, using baseline values of the three outcome measures as covariates [30].

\section{Risks and anticipated benefits for trial participants and society, including how the benefits justify the risks} Patients with substance use disorders and co-morbid personality disorder experience a number of serious problems. Patients with co-morbid personality disorder tend to remain symptomatic long after treatment $[7,8]$, and patients with some co-morbid personality disorders tend to commit a substantial amount of the crime that substance abusers commit [31].

If the findings of this study show that personality assessment can significantly improve the functioning of patients with substance use disorders, this can have significant impacts on both the quality of life of patients, and on society.

The main risk of this study is that patients experience a worsening of psychiatric symptoms or substance use as a reaction to receiving a feedback concerning their own personal functioning. There is some indication that symptoms may fail to improve with focus on personality, even if this focus improves substance use and therapeutic alliance [9]. We will monitor psychiatric symptoms every 3 months during the study, and patients have access to caseworker, psychiatrist and psychologist at the treatment centre.

\section{Ethical approval}

Institutional Review Boards in Denmark do not approve or disapprove of trials or other studies of psychosocial interventions. The medical director of social medicine in the City of Copenhagen, M.D. Peter Ege, read and approved the protocol in Danish. Patients will be given full information about the nature of the study, and be asked to give informed consent. Patients who refuse participation in the study will be given full access to all regular treatment services in the organisation, similar to the control group.

Ethically, the issues related to this study concerns the consequences of receiving serious diagnoses for which there is no clear and simple treatment, in particular personality disorders. However, although there is no simple treatment, patients are given suggestions and support, and have access to the support of the treatment centres

When patients in this trial are assessed, they also receive feedback and advice about how to handle the issues involved, and their caseworkers are given feedback and advice on how to best support patients.

\section{Discussion}

This paper describes the study protocol of a randomized controlled trial concerning personality disorder assessment and feedback versus an open interview. The aim of this study is to assess the potential value of personality disorder assessment for referral and casework in a real-life setting. The study design described above has specific strengths and limitations.

The study has a single-blind design, where patients are unaware if their treatment is designated as an "experimental" or "control" treatment. Follow-up interviewers are blinded to allocation, and we have procedures to reduce the risk that follow-up interviewers are made aware of subjects' status (i.e., follow-up interviewers make contact with patients before randomization is known; patients are told not to disclose details about the interview to the follow-up interviewers).

The study uses an attention placebo design, which means that the effects of time and attention are controlled for. Research has shown strong assessment reactivity in substance use outcome [20], meaning that patients who are exposed to assessment show improvement only for that reason. The amount of contact is controlled for in this 
trial. This means that if significant effects are found, they give strong support to the efficacy of personality disorder assessment.

The setting in which the study takes place is a community service. This means that although training and supervision is provided for caseworkers, the caseworkers are not primarily working with the research project. While this may reduce the potential efficacy of the intervention, it means that the study is in a sense between an efficacy trial and an effectiveness study.

\section{Competing interests}

The first author of the article, $\mathrm{MH}$, occasionally does paid training in understanding and assessing personality disorders.

\section{Authors' contributions}

MH originally conceived of the study, and wrote the application to the Health Insurance Fund. MH drafted the manuscript, but both authors reviewed it and MKP added substantial practical details and points to the manuscript.

\section{Acknowledgements}

This study is supported by a grant from the Danish Health Insurance Fund, Grant \#2007D202 to Head of Department Mads Uffe Pedersen. We want to acknowledge the ideas and support of associate professor Mats Fridell, Ph.d., Lund University, director of research and development Ringgaarden Addictive Behaviors Treatment Centre, Per Nielsen Ph.d., and Head of Department of the Centre for Alcohol and Drug Research, Mads Uffe Pedersen, Ph.d.

\section{References}

I. Grant BF, Stinson FS, Dawson DA, Chou PS, June Ruan W, Pickering $\mathrm{R}$ : Co-occurrence of I 2-month alcohol and drug use disorders and personality disorders in the United States. Results from the National Epidemiologic Survey of Alcohol and Related Conditions. Archives of General Psychiatry 2004, 6I:36I-368.

2. Verheul R: Co-morbidity of personality disorders in individuals with substance use disorders. European Psychiatry 200I, 16:274-282.

3. Siqueland L, Crits-Christoph P, Frank A, Daley D, Weiss R, Chittams J, Blaine J, Luborsky L: Predictors of dropout from psychosocial treatment of cocaine dependence. Drug Alcohol Depend 1998, 52(I):I-I3.

4. Kokkevi A, Stefanis N, Anastasopoulou E, Kostogianni C: Personality disorders in drug abusers: prevalence and their association with AXIS I disorders as predictors of treatment retention. Addictive Behaviors 1998, 23:84I-853

5. Hoffart A, Hedley LM, Thornes K, Larsen SM, Friis S: Therapists' emotional reactions to patients as a mediator in cognitive behavioural treatment of panic disorder with agoraphobia. Cognitive and Behavioral Therapy 2006, 35:174-182.

6. Betan E, Heim AK, Zittel Conklin C, Westen D: Countertransference phenomena and personality pathology in clinical practice: an empirical investigation. American Journal of Psychiatry 2005, 162:890-898.

7. McKay JR, Alterman AI, Cacciola JS, Mulvaney FD, O'Brien CP: Prognostic significance of antisocial personality disorder in cocaine-dependent patients entering continuing care. J Nerv Ment Dis 2000, 188(5):287-296.

8. Bakken K, Landheim AS, Vaglum P: Access Axis I and II disorders as long-term predictors of mental distress: a six-year pro- spective follow-up of substance-dependent patients. BMC Psychiatry 2007, 7:29.

9. Ball SA: Comparing individual therapies for personality disordered opioid dependent patients. Journal of Personality Disorder 2007, 2 I:305-32I.

10. Ball SA, Cobb-Richardson P, Connolly AJ, Bujosa CT, O'Neall T W: Substance abuse and personality disorders in homeless dropin center clients: symptom severity and psychotherapy retention in a randomized clinical trial. Comprehensive Psychiatry 2005, 46:37I-379.

II. Nielsen P, Røjskjær S, Hesse M: Personality-guided treatment for alcohol dependence: A quasi-randomized experiment. American Journal on Addictions 2007, 16:357-364.

12. Mataix-Cols D, Cowley AJ, Hankins M, Schneider A, Bachofen M, Kenwright M, Gega L, Cameron R, Marks IM: Reliability and validity of the Work and Social Adjustment Scale in phobic disorders. Comprehensive Psychiatry 2005, 46:223-228.

13. Veldhuizen S, Cairney J, Kurdyak P, Streiner DL: The sensitivity of the $\mathrm{K} 6$ as a screen for any disorder in community mental health surveys: a cautionary note. Canadian Journal of Psychiatry 2007, 52:256-259.

14. Kessler RC, Adler LA, Gruber MJ, Sarawate CA, Spencer T, Van Brunt DL: Validity of the World Health Organization Adult ADHD Self-Report Scale (ASRS) Screener in a representative sample of health plan members. International Journal of Methods in Psychiatric Research 2007, 16:52-65.

15. Darke S, Hall W, Wodak A, Heather N, Ward J: Development and validation of a multi-dimensional instrument for assessing outcome of treatment among opiate users: the Opiate Treatment Index. British Journal on Addictions 1992, 87:733-742.

16. Joe GW, Simpson DD, Broome KM: Retention and patient engagement models for different treatment modalities in DATOS. Drug Alcohol Depend 1999, 57(2): I I3-125.

17. Banerjee $P$, Duggan $C$, Huband N, Watson N: Brief psychoeducation for people with personality disorder: a pilot study. Psychology and Psychotherapy 2006, 79:385-394.

18. Etter JF, Perneger TV: A comparison of two measures of stage of change for smoking cessation. Addiction 1999, 94: I88I-I889.

19. McLellan AT, Luborsky L, Cacciola J, Griffith J, Evans F, Barr HL, O'Brien CP: New data from the Addiction Severity Index. Reliability and validity in three centers. J Nerv Ment Dis 1985, 173:412-423.

20. Clifford PR, Maisto SA, Davis CM: Alcohol treatment research assessment exposure subject reactivity effects: part I. Alcohol use and related consequences. J Stud Alcohol Drugs 2007, 68(4):519-528.

2I. Gossop M, Darke S, Griffiths P, Hando J, Powis B, Hall W, Strang J: The Severity of Dependence Scale (SDS): psychometric properties of the SDS in English and Australian samples of heroin, cocaine and amphetamine users. Addiction 1995, 90:607-6I4.

22. Moran P, Leese M, Lee T, Walters P, Thornicroft G, Mann A: Standardised Assessment of Personality - Abbreviated Scale (SAPAS): preliminary validation of a brief screen for personality disorder. British Journal of Psychiatry 2003, 183:228-232.

23. Hesse M, Rasmussen J, Pedersen MK: Standardised assessment of personality - a study of validity and reliability in substance abusers. BMC Psychiatry 2008, 8:7.

24. Grant BF, Dawson DA, Stinson FS, Chou PS, Kay W, Pickering R: The Alcohol Use Disorder and Associated Disabilities Interview Schedule-IV (AUDADIS-IV): reliability of alcohol consumption, tobacco use, family history of depression and psychiatric diagnostic modules in a general population sample. Drug Alcohol Depend 2003, 7 I(I):7-16.

25. Parker G, Hadzi-Pavlovic D: A question of style: refining the dimensions of personality disorder style. Journal of Personality Disorder 200I, 15:300-318.

26. Ames DR, Rose P, Anderson CP: The NPI-16 as a short measure of narcissism. Journal of Research in Personality 2006, 40:440-450.

27. Hasin D, Samet S, Nunes E, Meydan J, Matseoane K, Waxman R: Diagnosis of comorbid psychiatric disorders in substance users assessed with the Psychiatric Research Interview for Substance and Mental Disorders for DSM-IV. American Journal of Psychiatry 2006, 163:689-696. 
28. Koten M, Samet S, Hasin D: PRISM 6.0 - Psychiatric Research Interview for Substance and Mental Disorders. New York, Psychiatric Institute: Columbia University; 2001:63.

29. Horvath AO, Greenberg LS: Development and validation of the Working Alliance Inventory. Journal of Counseling Psychology 1989 , 36:223-233.

30. Hedeker D, Gibbons RD: MIXOR: a computer program for mixed-effects ordinal regression analysis. Computer Methods \& Programs in Biomedicine 1996, 49:157-176.

31. Fridell M, Hesse M, Billsten J: Criminal behavior in antisocial substance abusers between five and fifteen years follow-up. American Journal on Addictions 2007, 16:10-14.

32. Kessler RC, Barker PR, Colpe LJ, Epstein JF, Gfroerer JC, Hiripi E, Howes MJ, Normand SL, Manderscheid RW, Walters EE, Zaslavsky AM: Screening for serious mental illness in the general population. Archives of General Psychiatry 2003, 60:184-189.

33. Hesse M, Pedersen MU: Antisocial personality disorder and retention: a systematic review. Therapeutic Communities: International Journal of Therapeutic Communities 2006, 27:495-504.

\section{Pre-publication history}

The pre-publication history for this paper can be accessed here:

http://www.biomedcentral.com/1471-244X/8/30/pre pub

Publish with Biomed Central and every scientist can read your work free of charge

"BioMed Central will be the most significant development for disseminating the results of biomedical research in our lifetime. "

Sir Paul Nurse, Cancer Research UK

Your research papers will be:

- available free of charge to the entire biomedical community

- peer reviewed and published immediately upon acceptance

- cited in PubMed and archived on PubMed Central

- yours - you keep the copyright 